\title{
Investigation of the Normal Blowing Approach to Controlling Wingtip Vortex Using LES
}

\author{
Yubiao Jiang, ${ }^{1}$ Wanbo Wang, ${ }^{2}$ Chen Qin ${ }^{(D)}{ }^{2}$ Patrick N. Okolo, ${ }^{3,4}$ and Kun Tang ${ }^{2}$ \\ ${ }^{1}$ School of Aeronautics, Northwestern Polytechnical University, Xi'an 710129, China \\ ${ }^{2}$ China Aerodynamics Research and Development Center, Mianyang 621000, China \\ ${ }^{3}$ Mechanical Engineering and Mathematical Sciences, Faculty of Technology, Design and Environment, Oxford Brookes University, \\ OX33 1HX Oxford, UK \\ ${ }^{4}$ Buildings Fluid Dynamics Ltd., Dublin, Ireland
}

Correspondence should be addressed to Chen Qin; qinchen@cardc.cn

Received 14 October 2020; Accepted 27 April 2021; Published 27 May 2021

Academic Editor: Ratneshwar Jha

Copyright (C) 2021 Yubiao Jiang et al. This is an open access article distributed under the Creative Commons Attribution License, which permits unrestricted use, distribution, and reproduction in any medium, provided the original work is properly cited.

\begin{abstract}
The characteristics and control of a wingtip vortex are of great significance when considering drag reduction and flight safety of transportation aircrafts. The associated aerodynamic phenomenon resulting from rolling up of a wingtip vortex includes boundary layer flow, shear layer separation, and vortex breakdown, while the interaction of a wingtip vortex with the airframe causes induced drag, wingtip noise, etc. This paper studies a normal blowing method utilized to control the wingtip vortex. Large eddy simulation (LES) technique applied to a straight NACA0012 wing having a chord length $(c)$ of $0.4 \mathrm{~m}$ is adopted for this study. The Reynolds number based on the chord length is $1.6 \times 10^{6}$ and the angle of attack is $12^{\circ}$. The computational approach utilized the dynamic Smagorinsky-Lilly subgrid model for 3D simulations. Normal blowing from a high aspect ratio jet from the wingtip lower surface was used to control the wingtip vortex. From $0.05 c$ to $0.30 c$, the blowing slit width was $1 \mathrm{~mm}$, with the slit exit treated as a velocity inlet boundary condition which supplied the blowing jet with a momentum coefficient of $0.28 \%$. Results of axial velocity and span-wise pressure distribution of the clean airfoil presented good agreement with known experimental data. LES results indicate that normal blowing suppresses the primary vortex strength, while the vortex core radius, maximum induced velocity, axial vorticity flux, and pressure peak of the primary vortex are reduced by $25 \%, 28 \%, 46 \%$, and $52 \%$, respectively. Flow field structures before and after blowing show that blowing suppresses the shedding, coiling, and convergence of the free vortex layers near the primary vortex. This study also shows that normal blowing generates a jetinduced vortex at the location of the secondary vortex, while backflow, volume expansion, and spiral burst can be observed in the jet-induced vortex. The bursting jet-induced vortex destroys the jet-like flow structure of the primary vortex at the trailing edge.
\end{abstract}

\section{Introduction}

Over the past few decades, wingtip vortex has become a primary research focus due to increasing usage of aircrafts and air transportation. Wingtip vortex can typically be regarded as an axial vortex [1], and its flow phenomenon is overly complex. Aerodynamic phenomena are often observed in the rolling up of a wingtip vortex [2-9]; these includes the boundary layer flow and shear layer separation, wake flow and vortex breakdown, etc. The interaction of the wingtip vortex with the edge side and airframe causes effects like induced drag [10], strain gradient wake flow [9], and wingtip noise [11]. These effects are potential threats to flight safety and further reduce flight efficiency through restrictions on the frequency of take-off and landing [4]. Therefore, a deeper understanding of the characteristics of a wingtip vortex and its control is greatly significant for future development of commercial aircrafts.

For a three-dimensional wing, due to the pressure difference between the lower and upper surfaces of the wingtip (especially the flap tip), a crossflow over the side edge of the wingtip occurs and forms a concentrated vortex. This three-dimensional effect is strongest near the wingtip, i.e., the wingtip vortex. Based on the characteristics of the flow 
field, Albano et al. [12] proposed a spatial division on the evolution of a wingtip vortex: the form-field, near-field, and farfield regions. Many studies have been carried out through experiments and numerical simulations [13-18] on the formation of a wingtip vortex and the flow structure at the near-field region. These studies concentrated more on wingtip vortex axial velocity, induced velocity, wingtip vortex strength, etc. The generation, evolution, dissipation, and instability of the wingtip vortex were studied and reported. The occurrence of a jet-like flow in the form-field region of the primary vortex is often reported and appears to be associated with several different flow features. Chow et al. [16] reported that the axial velocity in the wingtip vortex core near the trailing edge could reach 1.77 times the freestream velocity. An experimental study by Anderson and Lawton [19] reported that the wingtip vortex strength possesses a linear relationship with axial velocity. Wu et al. [1], Batchelor [5], and Hoffmann and Joubert [7] studied the effects of axial velocity on the axial vortex system and they reported that the axial velocity remains crucial for vortex breakdown: the bubble burst and spiral burst mode.

Control of the wingtip vortex has drawn increasing research attention since the 1970s when Whitcomb [20], who worked in the NASA Langley Research Centre, proposed winglets that could improve the overall aerodynamic performance. Winglets are now widely used in transport aircrafts, especially commercial aircrafts. However, as a passive flow control approach, these winglets are still not suitable for a variety of application conditions.

In more recent years, documented literatures show that active flow control (AFC) approach possesses greater potentials for improving the performance of aircrafts. Various research has been conducted on active flow control of the wingtip vortex using applications such as plasma [21, 22], zero mass jet [23], and blowing [24-31]. Related research results $[21,27,32,33]$ show that span-wise excitation promotes the vortex core to move further away from the wing by increasing the effective span-wise length of the wing. This increases the momentum transfer between the shear layer and main flow, which results in weakening the wingtip vortex. Stream-wise excitation $[28,30]$ generates the counterrotating vortex pair which utilizes cross-stream instability [31] to weaken the vortex strength and promote viscous dissipation of the concentrated vortex. Yang [32] and Margaris and Gursul [33] conducted normal blowing on the wingtip. PIV measurement results showed that normal blowing promotes momentum transport and accelerates the merging of vortices, which is quite similar to span-wise blowing. However, it has been challenging for most experimental methods to observe data at the flow field much nearer to the wingtip. Therefore, the flow structure and physical mechanism should be studied further on account of limitations of spatiotemporal evolution data of the form-field and near-field regions.

Majority of published and documented literatures related to blowing control of the wingtip vortex were more focused on the span-wise blowing, with normal blowing expected to be further investigated especially due to lack of detailed analysis of its flow structures. Therefore, in this current paper, large eddy simulation (LES) is adopted to obtain the spatiotemporal evolution of the flow field near the wingtip. This study focuses on the generation, evolution, and breakdown of the wingtip vortex before and after normal blowing. Some key parameters such as pressure peak, induced velocity, axial velocity, axial vorticity flux, and flow structure of the wingtip vortex are discussed and analysed. Results of this current research paper can be used to better understand the flow structures of a wingtip controlled by normal blowing, and findings of this paper will provide support for the application of blowing as an active control technology in practical engineering problems.

\section{Simulation Methodology}

2.1. Governing Equations and Solver. The governing equation is the three-dimensional unsteady Navier-Stokes (NS) equation, and this governing equation in integral form is given by

$$
\frac{\partial}{\partial t} \iiint_{\Omega} \mathbf{Q} d \Omega+\iint_{\partial \Omega} \mathbf{F}(\mathbf{Q}) \bullet \mathbf{n} d S=\iint_{\partial \Omega} \mathbf{G}(\mathbf{Q}) \bullet \mathbf{n} d S .
$$

The expressions of the conservation variable, velocity vector, inviscid flux, and viscous flux are as follows:

$$
\begin{aligned}
& \mathbf{Q}=\left[\begin{array}{c}
\rho \\
\rho u \\
\rho v \\
\rho w \\
\rho e
\end{array}\right], \\
& \mathbf{V}=\left[\begin{array}{l}
u \\
v \\
w
\end{array}\right], \\
& \mathbf{F}=\left[\begin{array}{c}
\rho \\
\rho u \\
\rho v \\
\rho w \\
\rho e+p
\end{array}\right] \mathbf{V}+p\left[\begin{array}{l}
0 \\
\mathbf{i} \\
\mathbf{j} \\
\mathbf{k} \\
0
\end{array}\right], \\
& \mathbf{G}=\left[\begin{array}{c}
0 \\
\tau_{x x} \mathbf{i}+\tau_{x y} \mathbf{j}+\tau_{x z} \mathbf{k} \\
\tau_{y x} \mathbf{i}+\tau_{y y} \mathbf{j}+\tau_{y z} \mathbf{k} \\
\tau_{z x} \mathbf{i}+\tau_{z y} \mathbf{j}+\tau_{z z} \mathbf{k} \\
\Theta_{x} \mathbf{i}+\Theta_{y} \mathbf{j}+\Theta_{z} \mathbf{k}
\end{array}\right], \\
& \Theta_{x}=u \tau_{x x}+v \tau_{x y}+w \tau_{x z}-q_{x}, \\
& \Theta_{y}=u \tau_{x y}+v \tau_{y y}+w \tau_{y z}-q_{y}, \\
& \Theta_{z}=u \tau_{z x}+v \tau_{z y}+w \tau_{z z}-q_{z},
\end{aligned}
$$

where $t$ is the time, $\boldsymbol{\Omega}$ is the volume of the control volume, $\mathbf{S}$ is the unit normal vector of the control volume, and $\rho$ and $p$ are the density and pressure, respectively. $u, v, w$ are velocity components in $x, y, z$ directions, respectively. $\mathbf{i}, \mathbf{j}, \mathbf{k}$ are the unit 


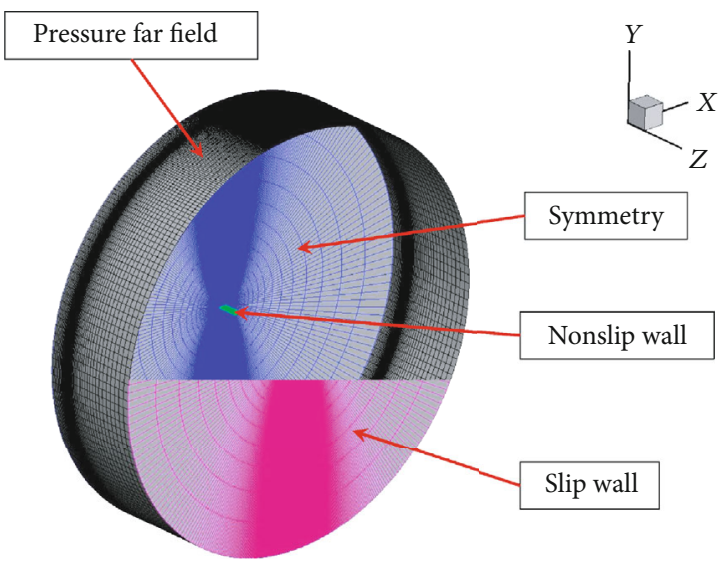

Figure 1: The boundary conditions in simulation.

vector in $x, y, z$ directions. $e$ is the total internal energy per unit mass. $\tau(\cdot)$ and $q(\cdot)$ are the stress term and heat conduction term, respectively.

By filtering the incompressible momentum equation, the following equations are obtained:

$$
\begin{gathered}
\frac{\partial \overline{u_{i}}}{\partial t}+\frac{\partial \overline{u_{i}} \overline{u_{j}}}{\partial x_{j}}=-\frac{1}{\rho} \frac{\partial \bar{p}}{\partial x_{i}}+v \frac{\partial^{2} \overline{u_{i}}}{\partial x_{j} \partial x_{j}}-\frac{\partial\left(\overline{u_{i} u_{j}}-\overline{u_{i}} \overline{u_{j}}\right)}{\partial x_{j}}, \\
\overline{\tau_{i j}}=-\left(\overline{u_{i} u_{j}}-\overline{u_{i}} \overline{u_{j}}\right) .
\end{gathered}
$$

Here, $\overline{\tau_{i j}}=-\left(\overline{u_{i} u_{j}}-\overline{u_{i}} \overline{u_{j}}\right)$ is also called the subgrid scale (SGS) Reynolds stress. The commercial CFD code ANSYS Fluent solver is utilized, where the dynamic SmagorinskyLilly model is used for simulations to overcome excessive dissipation of the Smagorinsky-Lilly vortex viscosity model [34], which easily ignores the large-scale fluctuations. Lily [35] and Germano et al. [36] constructed a dynamic process to solve the momentum equation by a second test filter operation. The difference between these two filtrations is mainly caused by the turbulence scale between the first filtering and the second filtering, which can be used to determine the Smagorinsky coefficient. The governing equations were discretized by the finite volume method, and the space discretization scheme utilized was the bounded central differencing scheme. By using the green Gauss node-based method, gradients of variables were calculated. The bounded second-order implicit scheme for time discretization combined with the dual time stepping method was applied to obtain the unsteady flow field. The dimensionless time step used was $t *=\Delta t \times U_{\infty} / c=0.0015$.

2.2. Grid and Boundary Conditions. In the airfoil coordinate system, $x, y$, and $z$ directions correspond to the chordwise, spanwise, and vertical directions, respectively. $x=0$ is the leading edge position of the airfoil. A 3D multiblock structured O-type grid topology is adopted in this present study, and the numerical domain size with boundary condition settings is as shown in Figure 1. The computational domain radius is approximately 25 times the chord length. The pressure far-field boundary condition is used for the far-field freestream, and the no-slip solid wall condition is used for the wing surface. To minimize computational costs, the symmetry boundary condition is used for the wing root plane. The side near the wingtip, $2.5 c$ away from the wingtip, is set as a sliding wall condition. In previous studies, the chord length is $c=0.4 \mathrm{~m}$ and freestream velocity $U_{\infty}=60 \mathrm{~m} / \mathrm{s}$. This velocity is in the landing speed range of an aircraft. In experiments [37, 38], flow separation was observed near the trailing edge for the angle of attack over $12^{\circ}$. To simulate the flow field of the flap edge, an angle of attack of $12^{\circ}$ is chosen for all simulation cases.

The span-wise grid near the wingtip is refined and optimized to improve computational efficiency. Details of the grid utilized is depicted in Figure 2, where the shape of cells in the span-wise section is optimized. The fine-grid region is extended by 1.5 times of the airfoil thickness to accurately capture shedding of the shear layer and roiling of the free vortex layers. The distance of the inner layer grid to the wall of the wingtip is consistent with the requirement of the wall boundary layer.

2.3. Normal Blowing Method. From 5\%c to $30 \%$, the blowing slit is located on the wingtip lower surface, as shown in Figure 3, in which the slit width is $h=0.25 \% c=1 \mathrm{~mm}$ and the blowing velocity $U_{j}=200 \mathrm{~m} / \mathrm{s}$. The blowing direction is in the normal direction (negative $y$ direction), and the blowing momentum coefficient is defined as follows:

$c_{\mu}=\frac{m_{j} V_{j}}{(1 / 2) \rho_{\infty} U_{\infty}^{2} S}=\frac{\rho_{j} U_{j}^{2} h l}{(1 / 2) \rho_{\infty} U_{\infty}^{2} c b}=\frac{\rho_{j}}{\rho_{\infty}}\left(\frac{U_{j}}{U_{\infty}}\right)^{2} \frac{h l}{c b}=0.28 \%$,

where $S$ is the reference airfoil area, $l$ is the chord-wise length of the slit, and $b$ is span-wise length of the wing. The blowing slit is set as a velocity inlet condition within the flow domain.

\section{Results and Discussion}

3.1. Validation of Simulation. Simulation of the clean airfoil was utilized for numerical verification. Three test cases were used with their grids and results as shown in Table 1.

The quality of the near-wall grid is always critical for accurate capture of flow structures within the boundary layer. Figure 4 shows the $y^{+}$values corresponding to the height of the grid first layer near the wingtip for case 2 (mesh 2). The simulation numerical results show that the $y^{+}$value of the wingtip area is less than 3 , while the $y^{+}$in most areas are less than 1 .

Accurate prediction of the axial velocity is highly paramount for the numerical simulation of the wingtip vortex because the wingtip vortex is predominantly the axial vortex. The axial velocity of the vortex core can be characterized by $x$ direction velocity $u$ (expressed in $U$ for distinction) to a certain degree. Table 1 also gives the comparisons for three test cases against published experimental results. The axial velocity near the vortex core as predicted by simulation shows to be in good agreement with previous documented experiments $[37,38]$ as plotted in Figure 5. Predicted pressure 


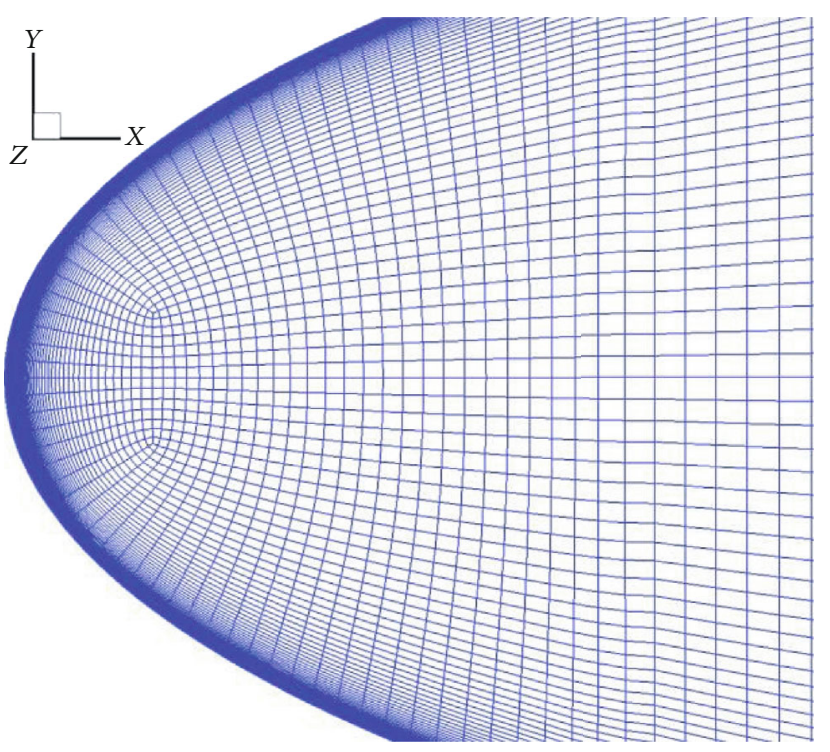

(a) Leading edge

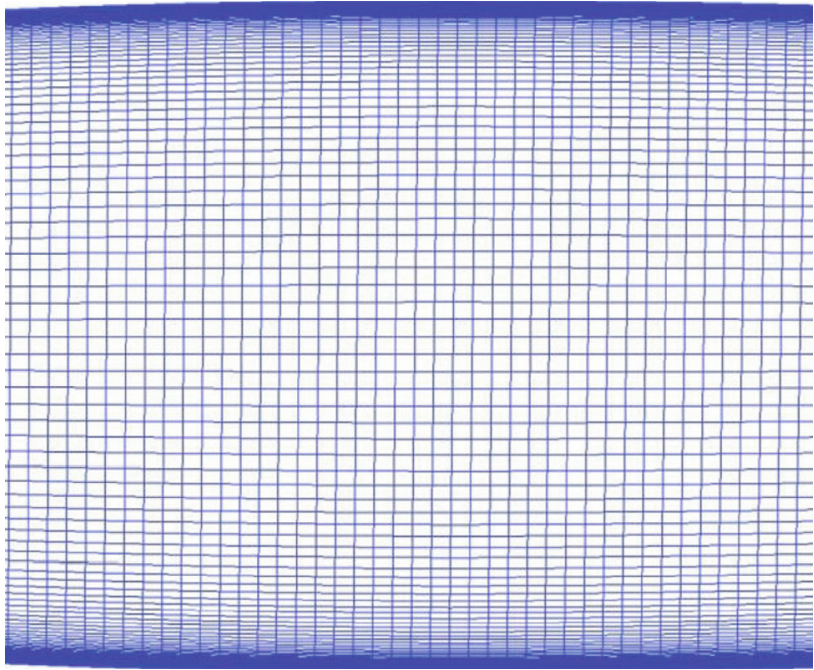

(b) Near maximum thickness

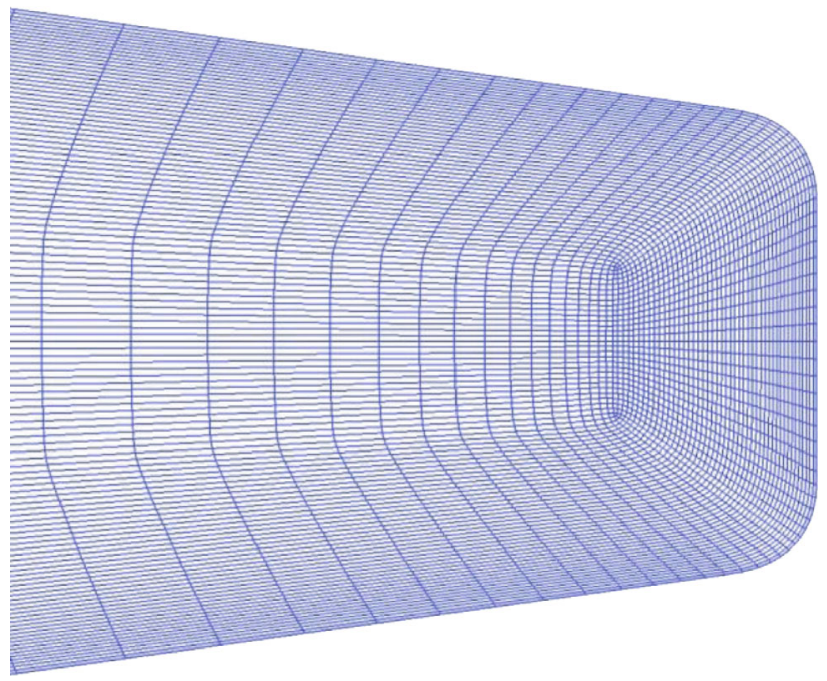

(c) Trailing edge

Figure 2: The spatial distribution of mesh at the wingtip.

distribution within the span-wise section is as shown in Figure 6, with this also in good agreement with experimental data. Therefore, while using mesh 2 , these results indicate that the numerical simulation adopted in present study can capture the wingtip vortex structure and pressure distribution of the wing. Hence, mesh 2 is utilized in performing subsequent simulations.

3.2. Baseline Flow. The structure of the wingtip vortex at different stream-wise sections is described in Figure 7. The primary vortex is generated on the upper wing surface, and the secondary vortex is generated near the wingtip end face (Figure $7(\mathrm{a})$ ), which is consistent with literatures $[15,16$, 19]. The secondary vortex flips from the end face to the upper surface and merges with the primary vortex at the section of $x / c=0.70$ (Figure 7(b)), thereby forming a big, concentrated wingtip vortex (Figure $7(\mathrm{c})$ ). The axial velocity of the primary vortex is significantly different from that of the secondary

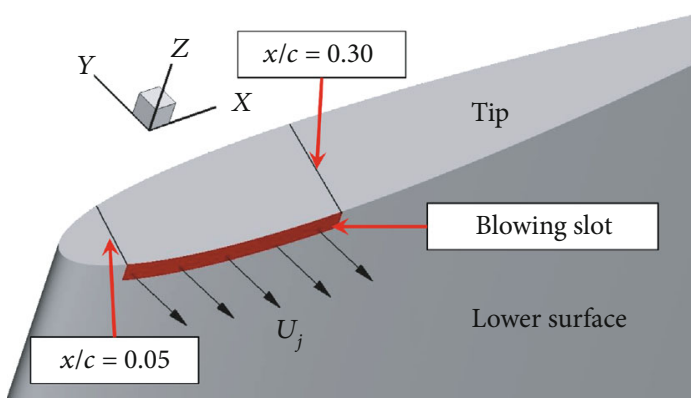

FIGURE 3: Schematic of normal blowing at the wingtip.

vortex. The axial velocity of the primary vortex is higher than that of the freestream and forms a stable jet-like flow [14-17]. For the secondary vortex, the axial velocity is lower than that of the freestream and forms an unstable wake-like flow. As 
TABLE 1: Test case and grid information used for verification.

\begin{tabular}{|c|c|c|c|c|}
\hline Test case & Case 1 & Case 2 & Case 3 & Exp \\
\hline Grid & Mesh 1 & Mesh 2 & Mesh 3 & - \\
\hline Along camber & 523 & 711 & 1038 & - \\
\hline Along radial direction & 91 & 96 & 126 & - \\
\hline Along span-wise direction & 151 & 161 & 188 & - \\
\hline Along maximum wing thickness & 97 & 121 & 131 & - \\
\hline Total $/ 10^{6}$ & 8.46 & 14.36 & 25.19 & - \\
\hline Axial velocity, $x / c=0.95$ & 1.38 & 1.45 & 1.50 & $\sim 1.53$ \\
\hline Axial velocity, $x / c=1.10$ & 1.33 & 1.40 & 1.46 & $\sim 1.45$ \\
\hline
\end{tabular}

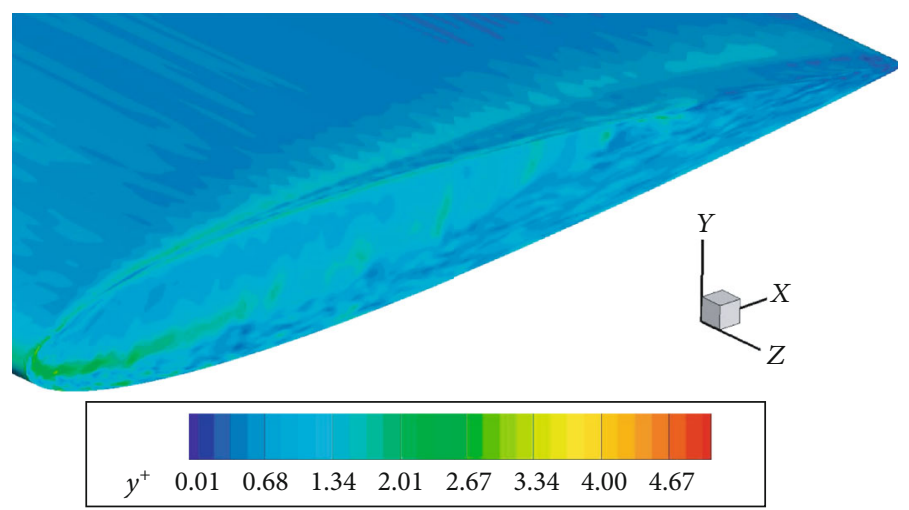

FIgURE 4: The distribution of $y^{+}$near the wingtip of case 2 .

shown in Figure 8, the jet-like flow structure of the primary vortex core expands as the location of the stream-wise section increases from $x / c=0.50$ to $x / c=0.95$, which indicates that the primary vortex plays an important role in the interaction of two vortices.

Based on $Q$ criterion [39], the 3D structures of the wingtip vortex at the trailing edge is obtained. In this present study, the $Q$ value is normalized as follows:

$$
Q_{\mathrm{var}}=\frac{Q}{1 / 2\left(\|\boldsymbol{\Omega}\|^{2}+\|\mathbf{S}\|^{2}\right)}=\frac{\left(\|\boldsymbol{\Omega}\|^{2}-\|\mathbf{S}\|^{2}\right)}{\left(\|\boldsymbol{\Omega}\|^{2}+\|\mathbf{S}\|^{2}\right)},
$$

where $\mathbf{S}$ is the strain rate tensor, which represents the contribution of pure deformation of fluid under incompressible conditions. $\boldsymbol{\Omega}$ is the eddy tensor, which represents the contribution of fluid rotation to deformation. $Q_{\text {var }}$ represents the relative magnitude of fluid rotation. Figure 9 shows the isosurface near the trailing edge with $Q_{\mathrm{var}}=0.3$ (coloured by the dimensionless axial velocity). It can be found that the wingtip rolls up and revolves around the jet-like flow structure of the primary vortex.

Figure 10 shows the instantaneous flow field of the $2 \mathrm{D}$ structure of the trailing edge $(x / c=1.10)$. Figure 10 (a) indicates that the axial vorticity distribution is fragmented in the wingtip vortex (due to Helmholtz instability) and the vorticity is basically in the same direction. Although the jet-like flow is in the centre of the wingtip vortex, as shown in Figure 10(b), yet, the region of the jet-like flow appears to be surrounded by the regions of the wake-like flow. This phenomenon was also recorded in the experiments conducted by Birch et al. [17] and Shekarriz et al. [40]. One reasonable explanation to this phenomenon involves the tangential velocity and free vortex layer from the boundary layer. Negative pressure is formed on the axis of the vortex core due to tangential velocity that develops downward and accelerates while the corresponding axial velocity is accelerated. The axial velocity of the free vortex layer is low due to velocity deficit in the boundary layer. Although the vortex core axial velocity portrays inhomogeneity under the influence of the nonuniform tangential velocity and velocity deficit of the free vortex layer, the jet-like flow is still dominant in the wingtip vortex because the free vortex layer and wake-like flow is entrained by the jet-like flow. The documented experiment of Anderson and Lawton [19] demonstrated that the wingtip vortex strength possesses a linear relationship with axial velocity. The result and analysis suggest that the robust jetlike flow structure within the primary vortex is crucial to the formation of the wingtip vortex.

3.3. Control Effect of Normal Blowing. In this present study, the near-field wingtip flow field changes greatly after normal blowing. The time-averaged flow field as described in Figure 11 shows that the primary vortex core pressure decreases to a certain extent upstream (Figure 11(a)), indicating that normal blowing suppresses generation of the primary vortex even though it does not directly act on the primary vortex. For the section of $x / c=0.50$ and $x / c=0.70$, 


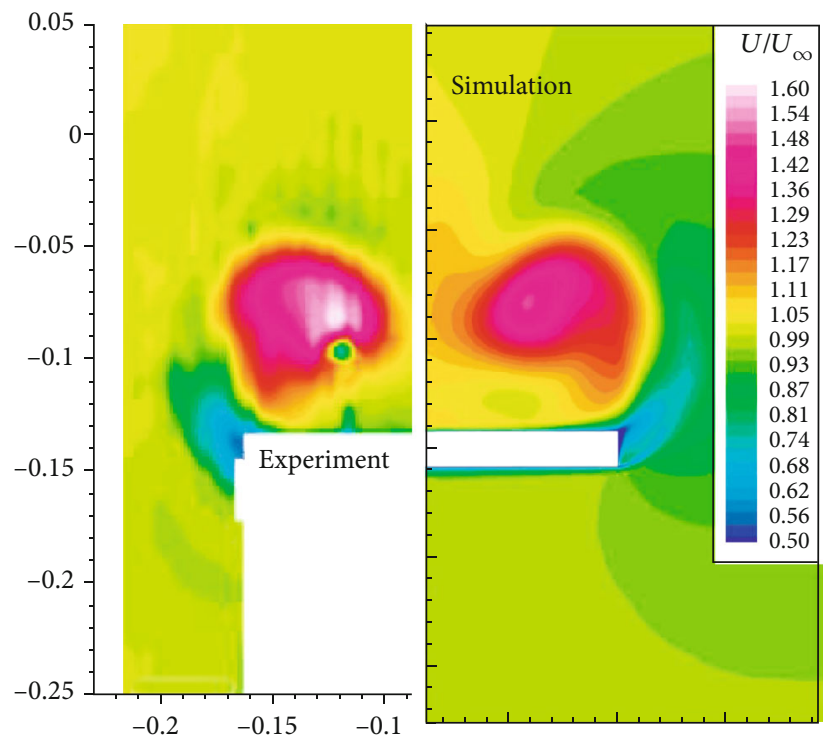

(a) $x / c=0.95$

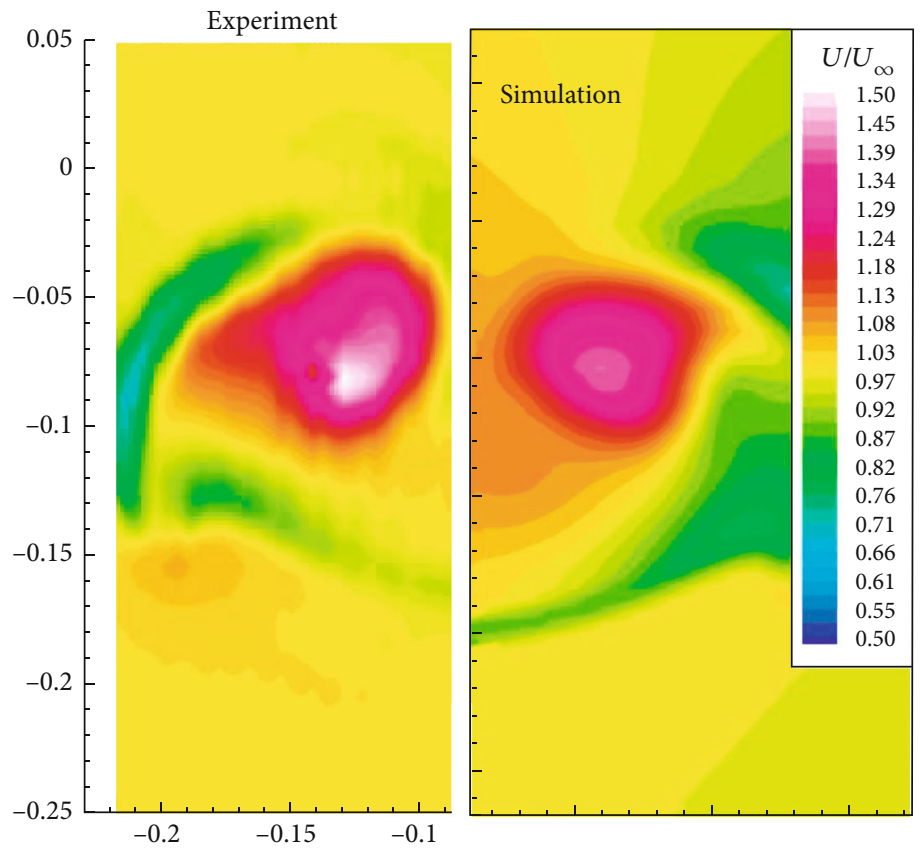

(b) $x / c=1.10$

Figure 5: The axial velocity distribution from experiments and simulation, case 2 .

as shown in Figures 11(a) and 11(b), respectively, the secondary vortex becomes stronger and evolves into the jet-induced vortex. For $x / c=0.95$, which is near the trailing edge, the primary vortex tends to dissipate under the interaction of the jet-induced vortex and is no longer the centre of the trailing vortex. Hence, the pressure of the jet-induced vortex decreases dramatically, which qualitatively coincides with the experimental results of Yang [32] and Margaris and Gursul [33]. Experimental data of Margaris and Gursul indicated that in most cases, blowing near the lower surface led to diffused vortices in the near wake.

The primary vortex before and after blowing is quantitatively analysed by the method proposed by Burley et al. [41] as follows:

$$
\begin{gathered}
C v=\frac{\sum\left(\omega_{x}\right)_{k} \cdot\left(x_{k}, y_{k}\right)}{\sum\left(\omega_{x}\right)_{k}}, \\
\Gamma_{r}=\iint \omega_{x} d A, \\
U_{r}=\frac{\Gamma_{r}}{2 \pi r},
\end{gathered}
$$

where the instantaneous position of the vortex core centre $\left(C_{v}\right)$ is obtained by the method shown in Figure 12. The axial vorticity flux $\left(\Gamma_{\mathrm{r}}\right)$ is obtained by integrating the stream-wise 


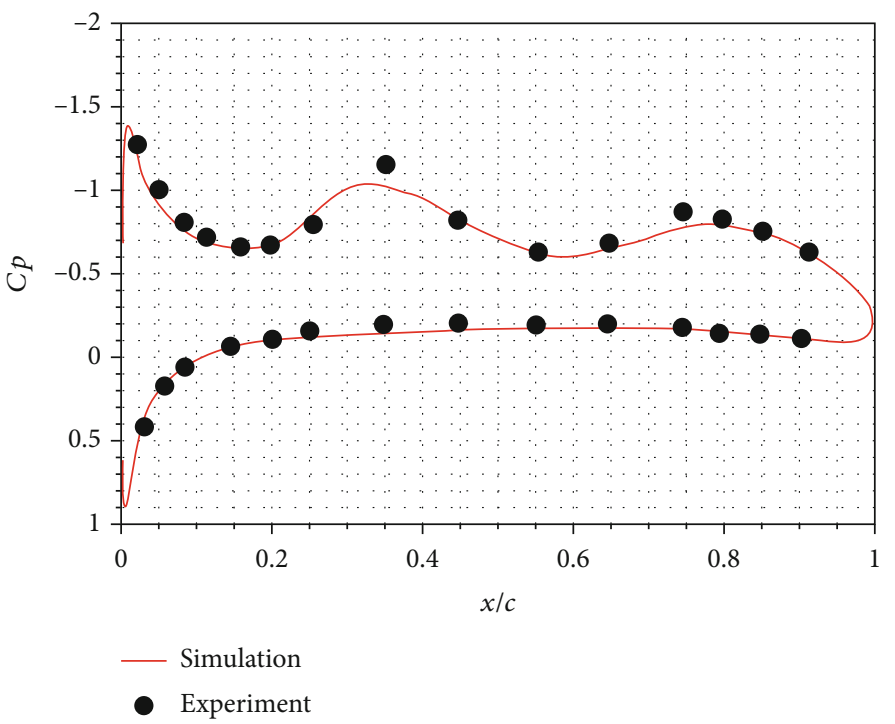

FIgURE 6: The pressure distribution at section $z / c=-2.25 \%$, case 2 .

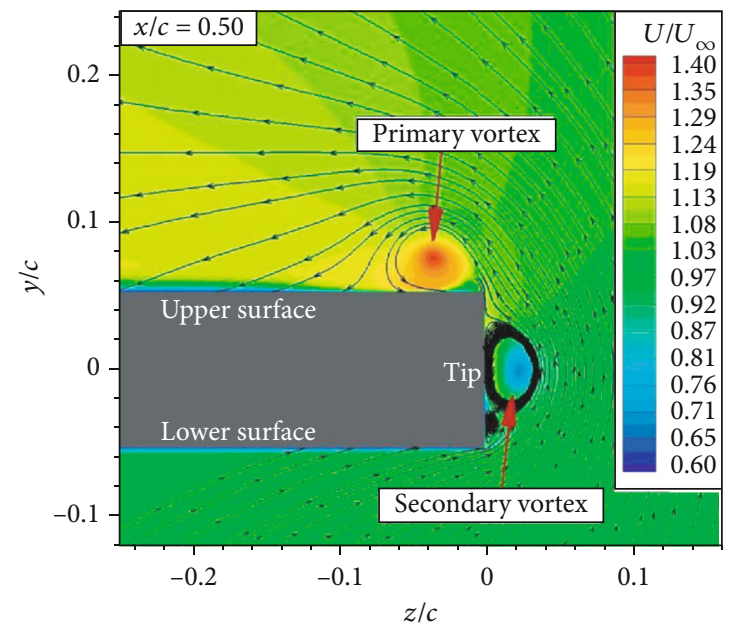

(a) $x / c=0.50$

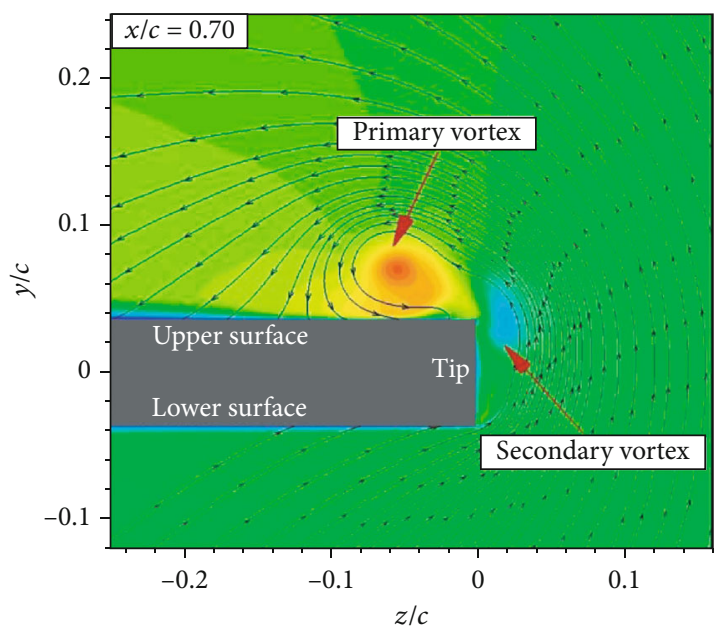

(b) $x / c=0.70$

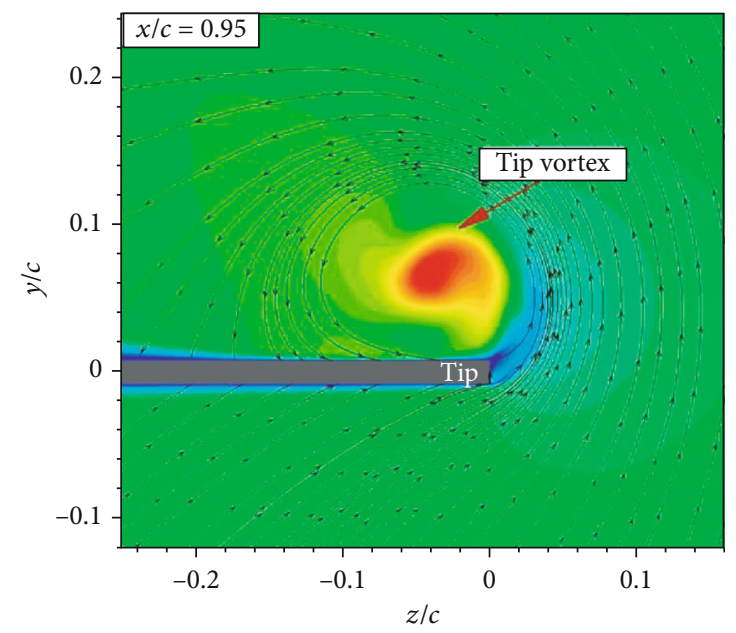

(c) $x / c=0.95$

FIgURE 7: The evolution of the wingtip vortex. 


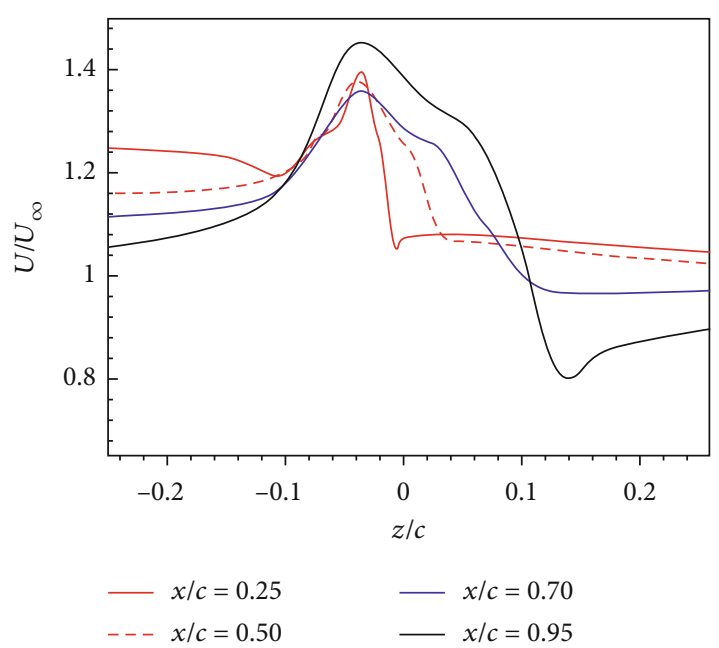

FIGURE 8: Axial velocity of the primary vortex.

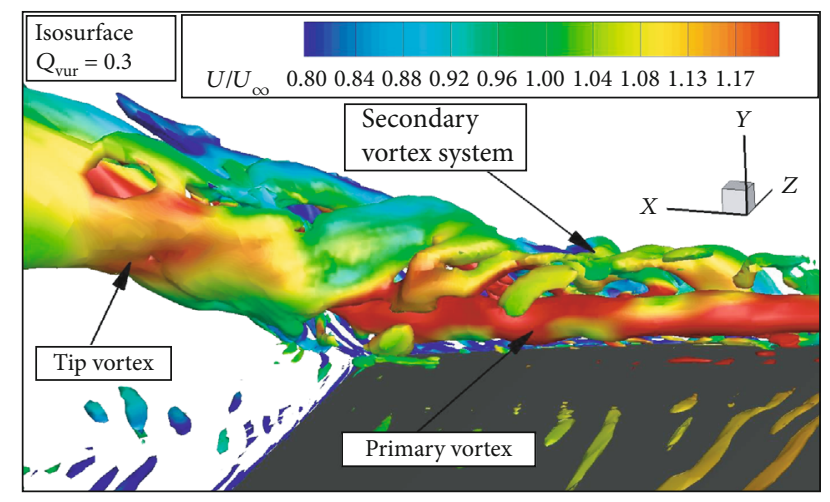

FIGURE 9: Wingtip vortex structure at the trailing edge of clean airfoil.

vorticity $\left(\omega_{x}\right)$ along the radial direction, and the induced velocity $\left(U_{r}\right)$ can be calculated subsequently. The induced velocity first increases and then decreases along the radial direction, which reaches a maximum $\left(U_{r_{-} \max }\right.$, nondimensionalized by freestream velocity) at a certain radius $\left(R_{\text {core }}\right)$. The radius of the vortex core can be characterized by $R_{\text {core }}$, and the corresponding axial vorticity flux ( $\Gamma_{\text {core }}$, nondimensionalized by $U / c \times 1 \mathrm{~m}^{2}$ ) can be used to represent the strength of the primary vortex.

Figures 13-15 show the effects of normal blowing on the radius, the axial vorticity flux, and the maximum induced velocity of the primary vortex core, respectively. Results of the clean airfoil show that the radius and strength of the primary vortex core increase significantly when $x / c \geq 0.70$. It also proves that the primary vortex plays a dominant role in rolling up of the wingtip vortex near the trailing edge. The secondary vortex provides many free vortex layers to the primary vortex and cooperates with the vortex merging and rolling up of the tip vortex. Under the control of normal blowing, the radius, maximum induced velocity, axial vorticity flux, and peak value of pressure of the primary vortex core decrease by $25 \%, 28 \%, 46 \%$, and $52 \%$, respectively. Especially in the downstream of $x / c=0.70$, the strength of the primary

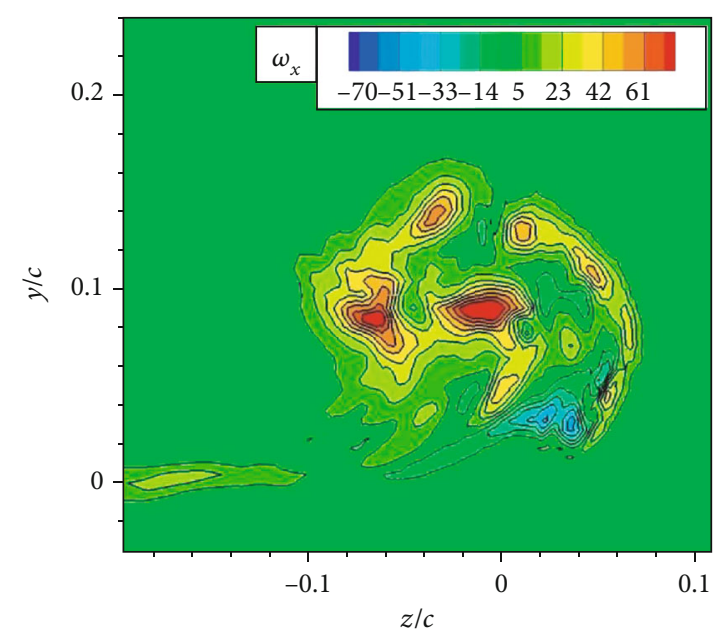

(a) $x / c=1.10, \omega_{x}$

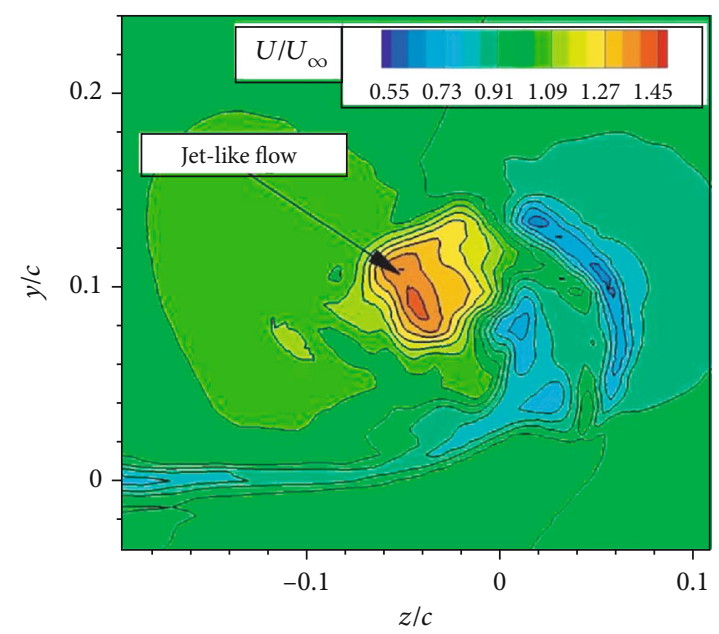

(b) $x / c=1.10, U / U_{\infty}$

FIGURE 10: Instantaneous flow field of the wingtip.

vortex is even weaker than that in the upstream (Figure 14). In addition, in the downstream of $x / c=0.70$, the difference between the baseline and control is larger than that in the upstream. It is shown that although normal blowing directly acts in the upstream $(x / c=0.05 \sim x / c=0.30)$, the effect of normal blowing on the primary vortex is mainly concentrated in the downstream region, which also coincides with the results of Yang [32] and Margaris and Gursul [33].

3.4. Vortical Structure. Albano et al. [12] and Chow et al. [16] proposed the crossflow velocity $\left(U_{c}=\sqrt{u^{2}+v^{2}}, u\right.$, and $v$ are the stream-wise velocity and the normal velocity, respectively) to describe the rolling up of the wingtip vortex. As shown in Figure 16, crossflow velocity around the wingtip of the baseline and control shows that the lateral flow near the secondary vortex is significantly enhanced but the lateral flow near the primary vortex is restrained. This is a major reason for the pressure decrease of the primary vortex shown in Figure 11(a). It appears that the normal blowing from the lower surface acts as a virtual wingtip plate to restrain the rolling up of the primary vortex on the upper surface, which is like span-wise blowing [25]. 

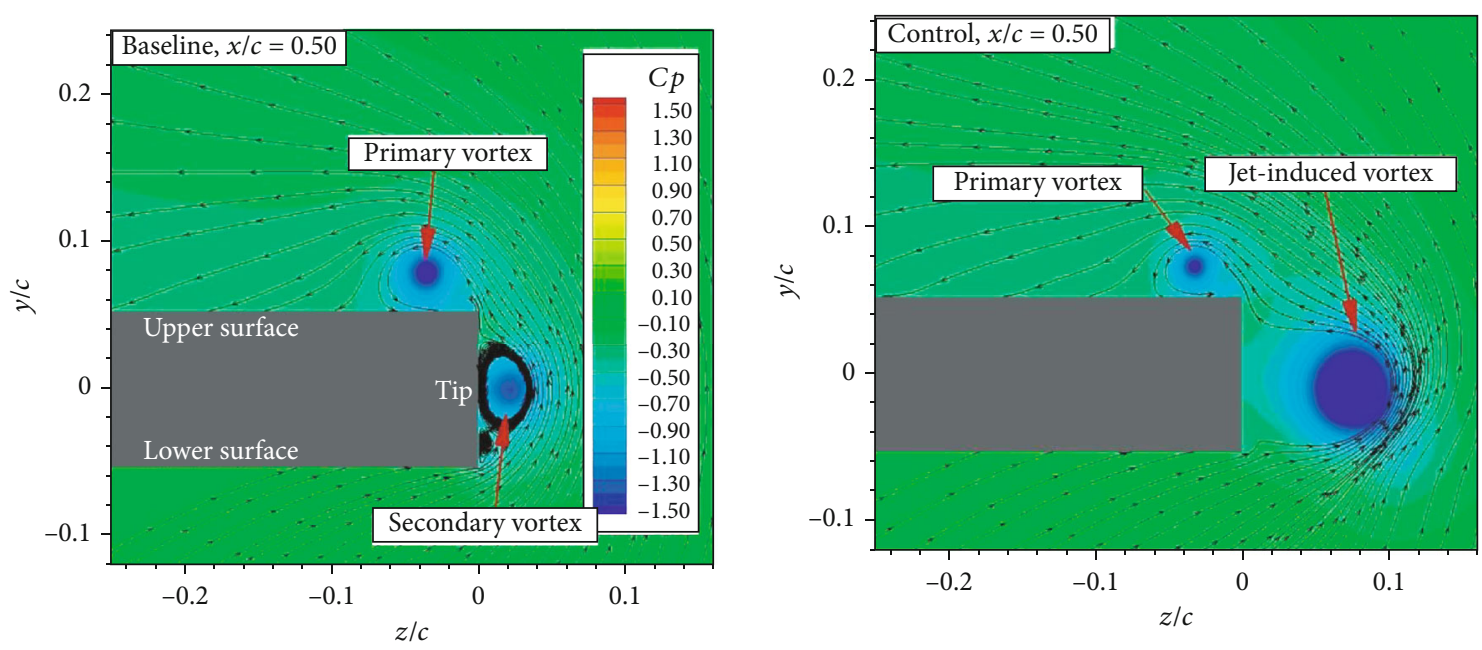

(a) $x / c=0.50$
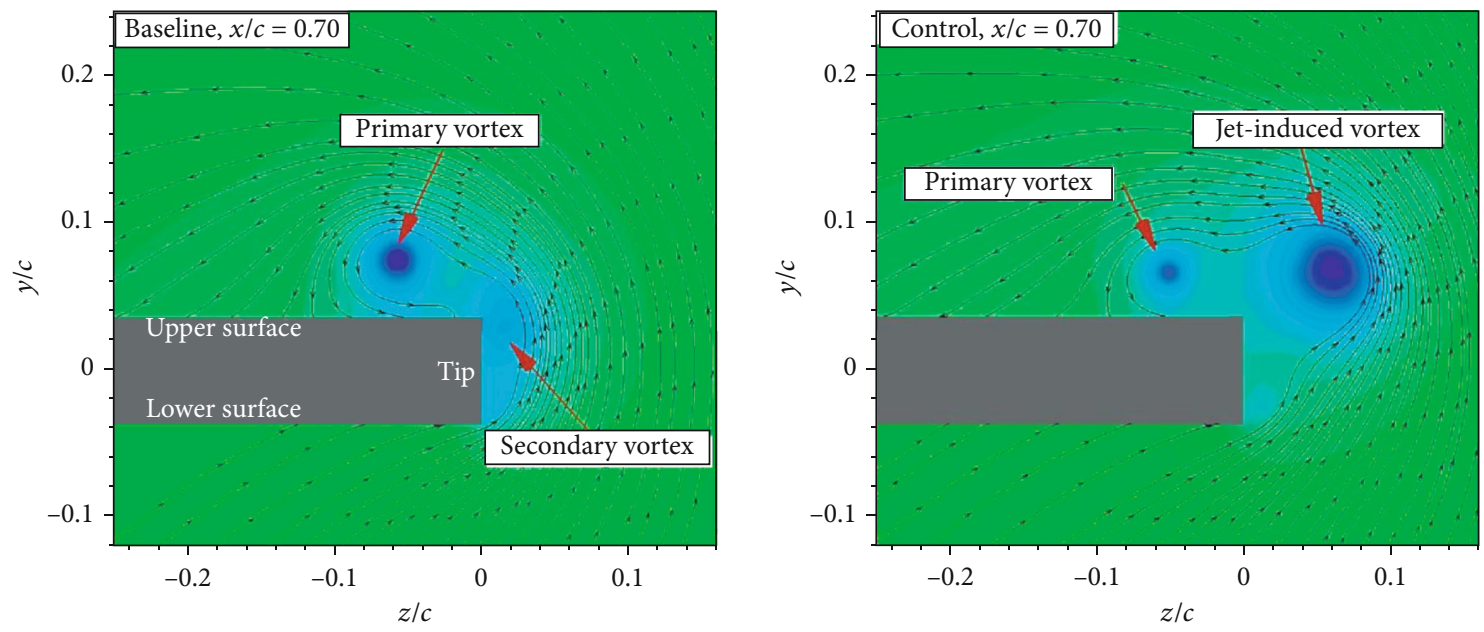

(b) $x / c=0.70$
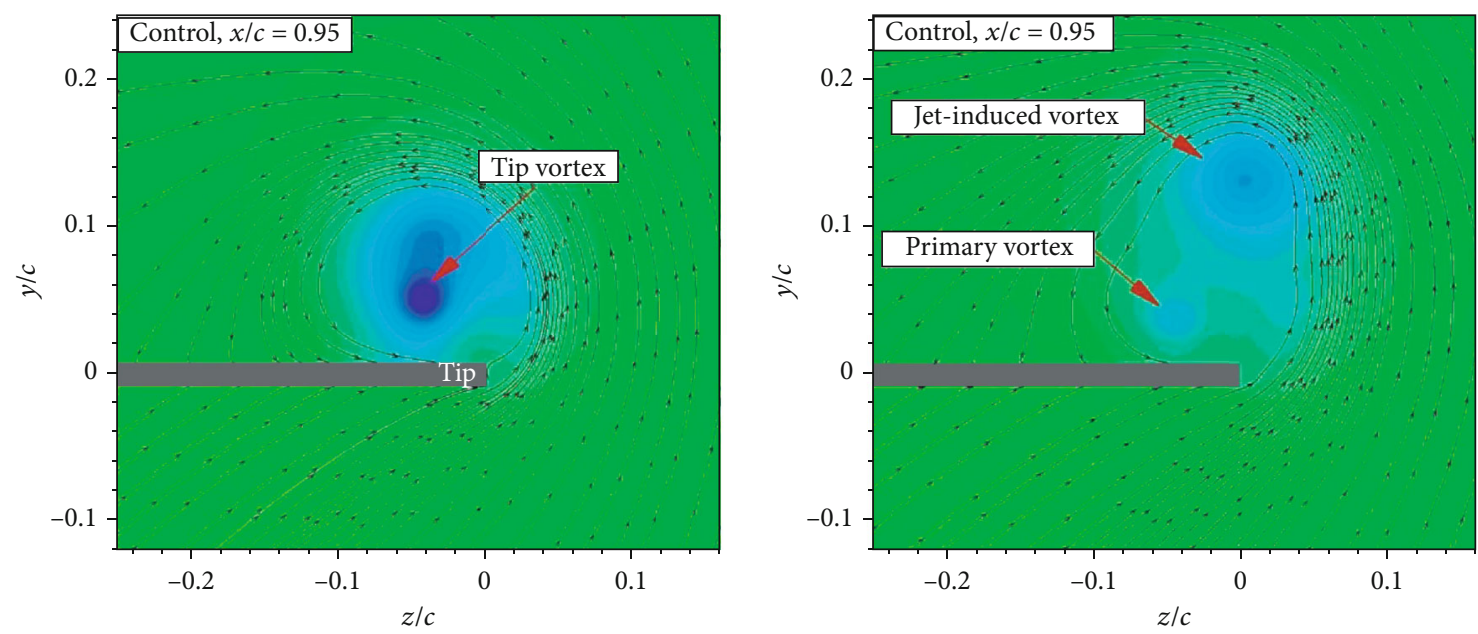

(c) $x / c=0.95$

FIgURE 11: Time-averaged flow field before and after normal blowing. 


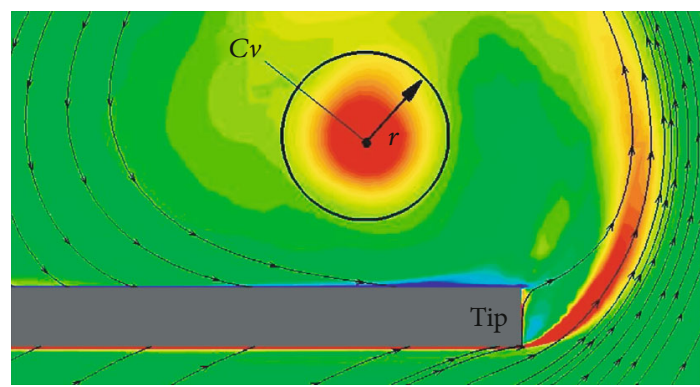

FIGURE 12: The schematic of quantitative analysis.

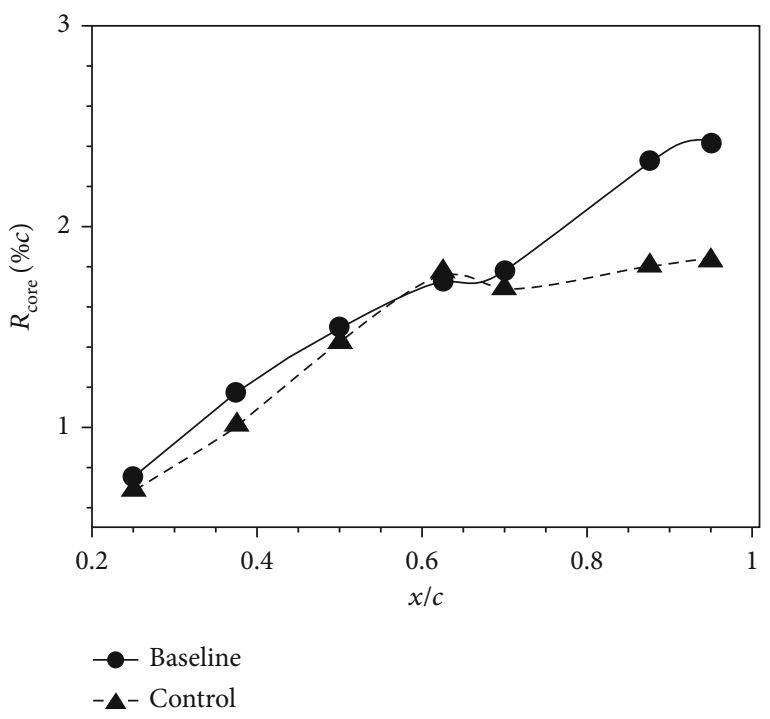

FIgURE 13: The radius of the vortex core.

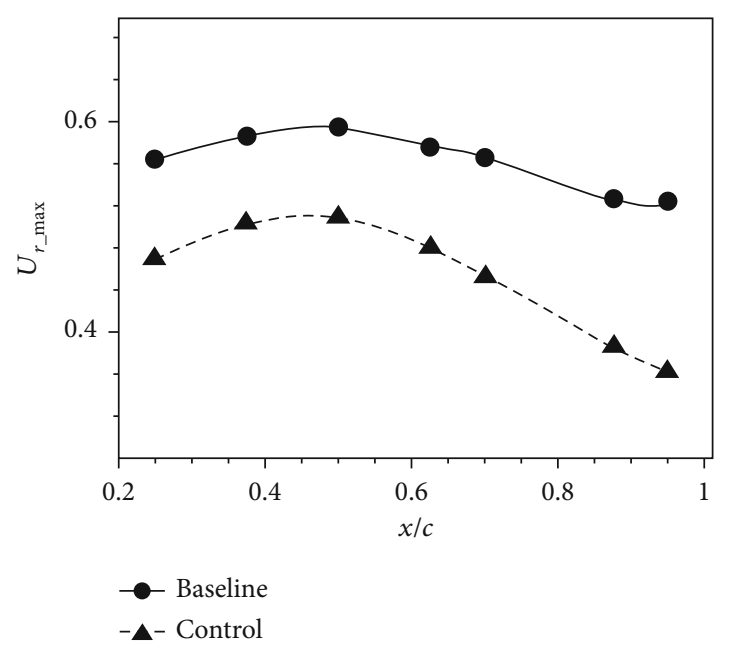

FIgURE 14: The axial vorticity flux of the vortex core.

The axial velocity around the wingtip flow field after blowing is analysed as shown in Figures 17 and 18, which show a comparison of the instantaneous distribution of the axial velocity. Like the time-averaged flow of Figure 7 , the jet-like flow structure dominates the primary vortex of the

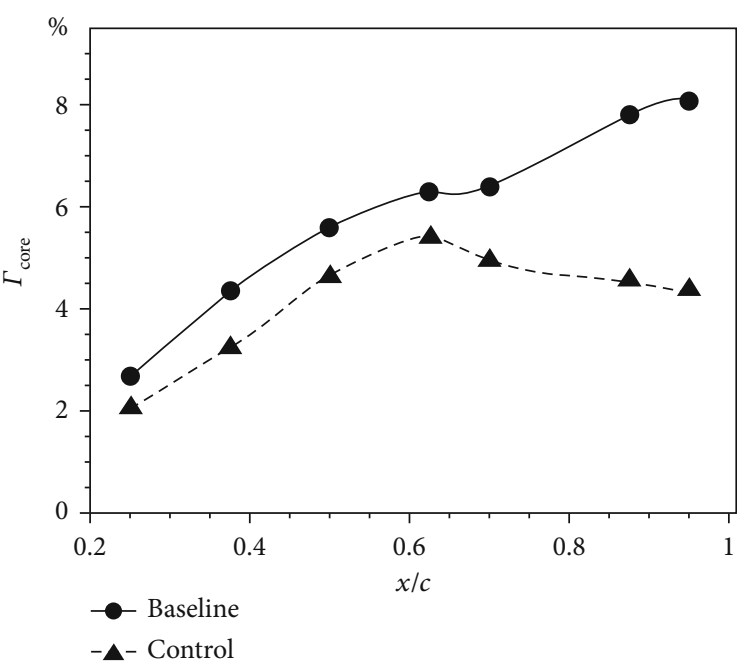

FIGURE 15: The maximum induced velocity.

clean airfoil instantaneous flow. After normal blowing, the axial velocity of the primary vortex tends to decrease. Furthermore, a wake-like flow structure appears in the primary vortex (Figure 18, section of $x / c=0.875$ ) and there exists a typical backflow in the jet-induced vortex generated by normal blowing (Figure 18, section of $x / c=0.25, x / c=0.375$, and $x / c=0.5)$. This indicates that the axial velocity in the vortex attenuates rapidly.

Wu et al. [1], Batchelor [5], and Hoffmann and Joubert [7] all pointed out that the axial velocity has important effects on the maintenance, acceleration, coiling, instability, and breakdown of the axial vortex. Anderson and Lawton [19] suggested that the strength of the wingtip vortex is linear with the axial velocity of the vortex core and the robust jet-like flow structure is crucial to the wingtip vortex stability. The decay of axial velocity of the primary vortex and the jetinduced vortex backflow after normal blowing causes a change to the trailing edge flow field significantly. As mentioned previously, Figure 11 shows that the pressure of the primary vortex decreases and is not dominant for rolling up of the wingtip vortex after blowing. Furthermore, according to the instantaneous axial vorticity distribution near the trailing edge, as shown in Figure 19, the secondary vortex and the free vortex layer shedding from the trailing edge provides momentum and vorticity to the primary vortex continuously. This accelerates the rolling up of the primary vortex for the clean airfoil. After applying blowing control, the primary vortex is smaller and weaker than that of the clean airfoil and the jet-induced vortex is large in scale but its vorticity is dispersed in different directions (Figures 20 and 21). It is worthy of note that the blowing results in counter-rotating vortex pairs (Figure 20, section of $x / c=0.25, x / c=0.375$, and $x / c=0.5$ ) accompanied by backflow (Figure 18). This result is likened to the experiment of Margaris and Gursul [33], even though the airfoil and manner of blowing used in their study is a bit different. Computational simulations $[28,29]$ showed that span-wise blowing near the tip produced inboard vortices that interacted with the wingtip vortex and reduced its strength. It is also found that the jet- 


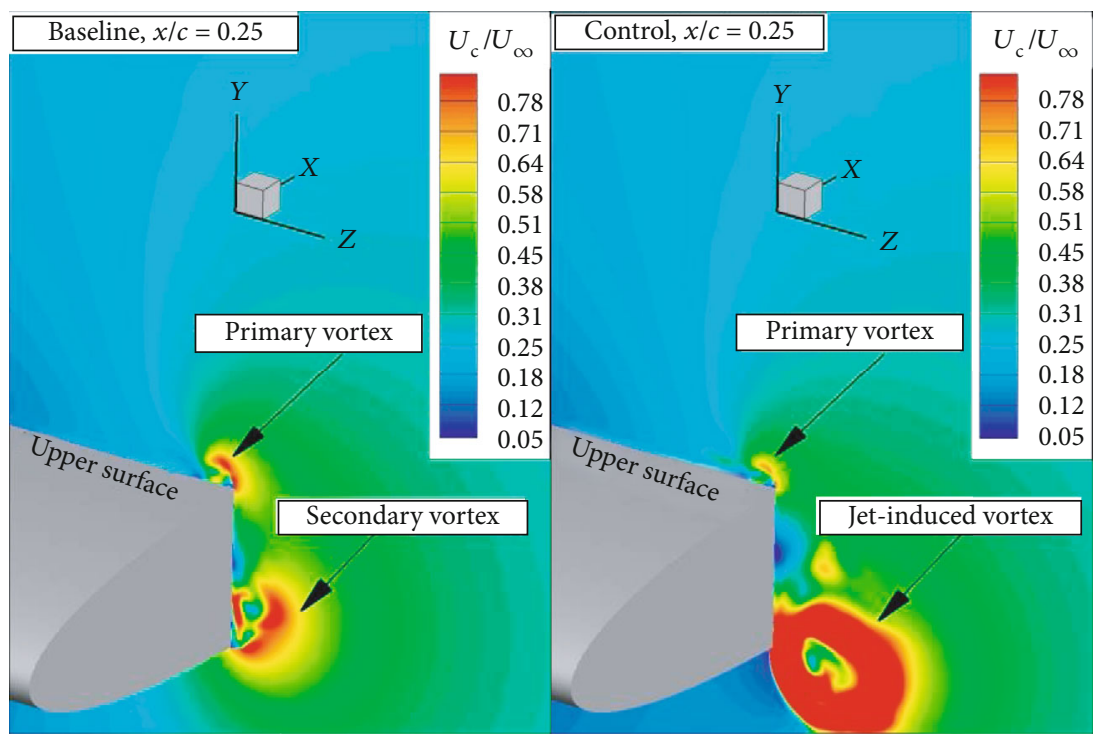

FIgURE 16: The lateral flow near the wingtip before and after normal blowing.

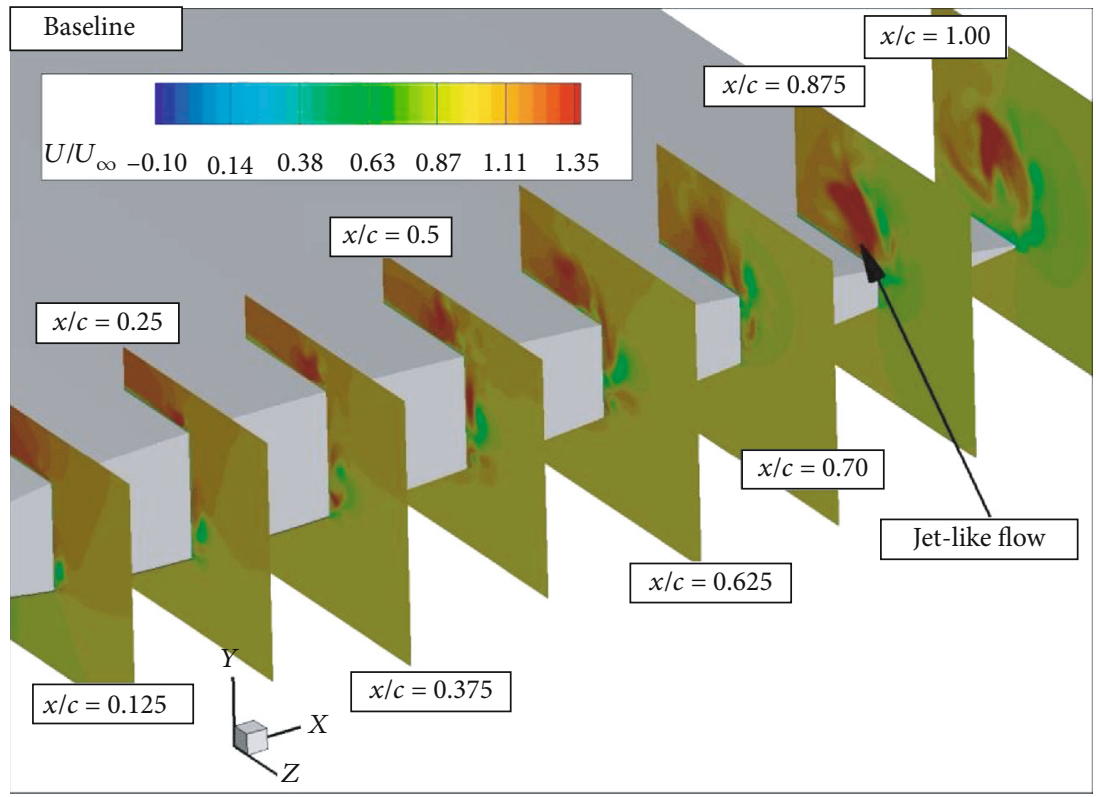

FIGURE 17: The axial velocity distribution of clean airfoil.

induced vortex of normal blowing from the lower surface can destroy the wingtip vortex thoroughly by eroding the jet-like flow of the primary vortex.

The bubble burst and spiral burst of the vortex are closely related to changes of axial velocity $[1,5,7]$. There are some obvious characteristics in the breakdown of the axial vortex [1]. Along the vortex axis, an internal stagnation point can be observed. A limited recirculation flow appears downstream the stagnation point and the volume of the vortex core expands dramatically. The recirculation flow is closely related to the axial velocity loss in the concentrated vortex core. The key to forming bubble burst and spiral burst is the presence of the internal stagnation point of the vortex. As shown in Figure 22, the position where the jet-induced vortex begins to break is near the region where the jet-like flow structure transforms into the wake-like flow structure. The vortex core downstream appears to explode and a vortex breakdown in the form of spiral structure can be observed. It is certain that vortex breakdown is also responsible for the pressure decline of the jet-induced vortex core shown in Figure 11. As previously mentioned, normal blowing weakens the jet-like flow structure of the primary vortex upstream. The wingtip vortex structure near the trailing edge after normal blowing is shown in Figure 23. When compared with the clean airfoil as shown in Figure 9, it is found that the spiral breakdown of the jet-induced vortex destroys the primary vortex and dominates the flow at the trailing edge. 


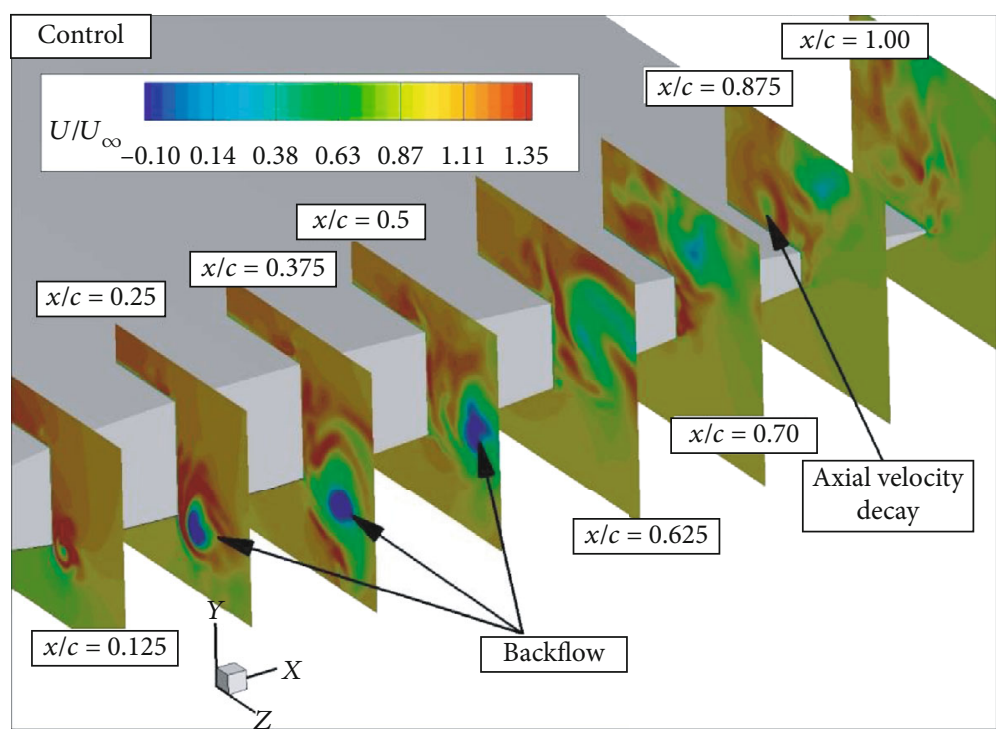

FIGURE 18: The axial velocity distribution under normal blowing.

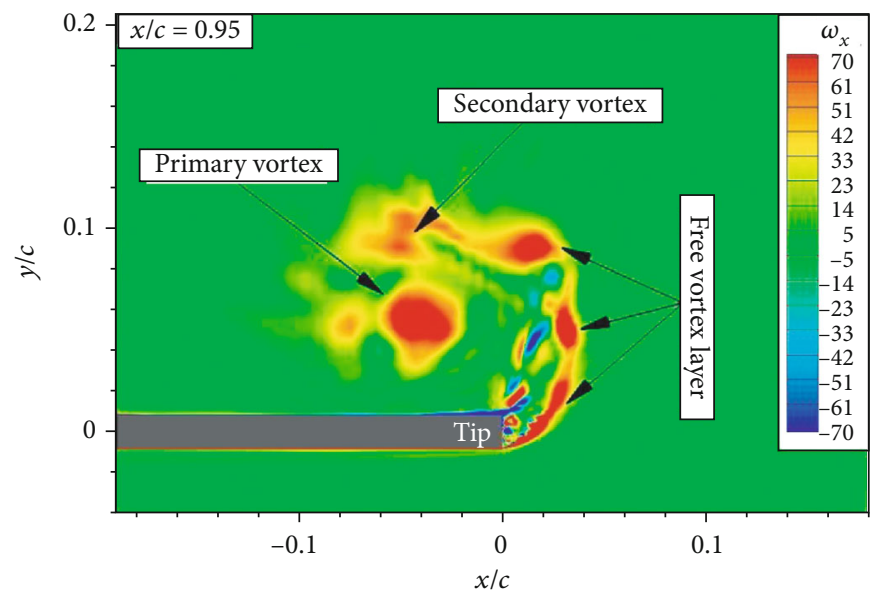

FigURE 19: The instantaneous vorticity field near the trailing edge of clean airfoil.

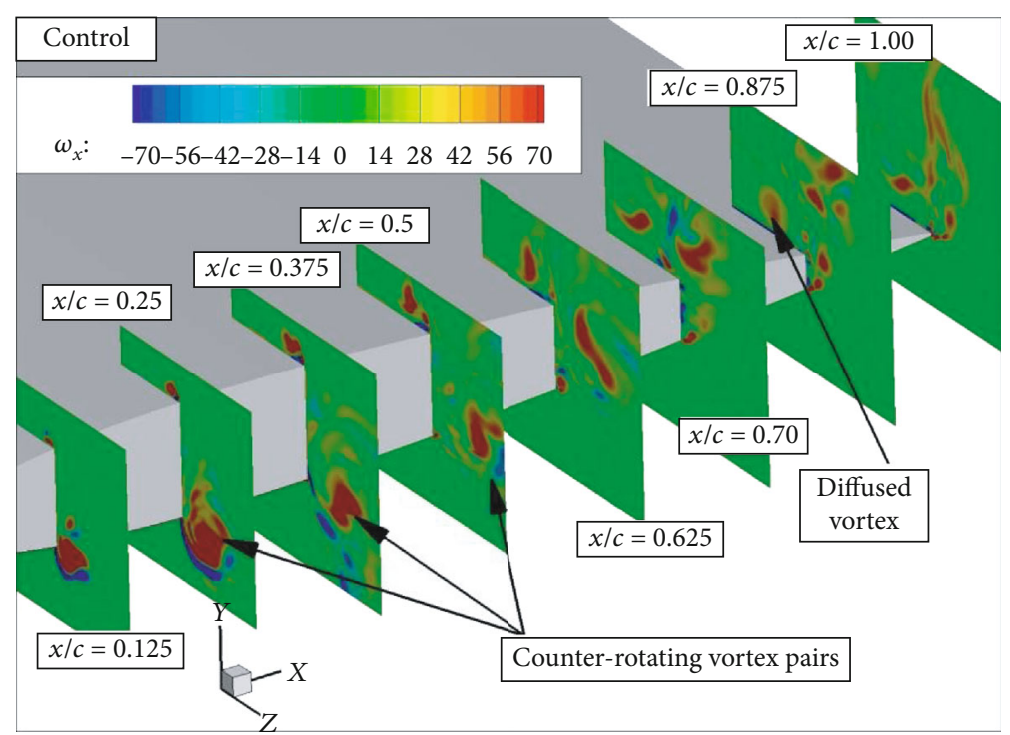

FIGURE 20: The axial vorticity distribution under normal blowing. 


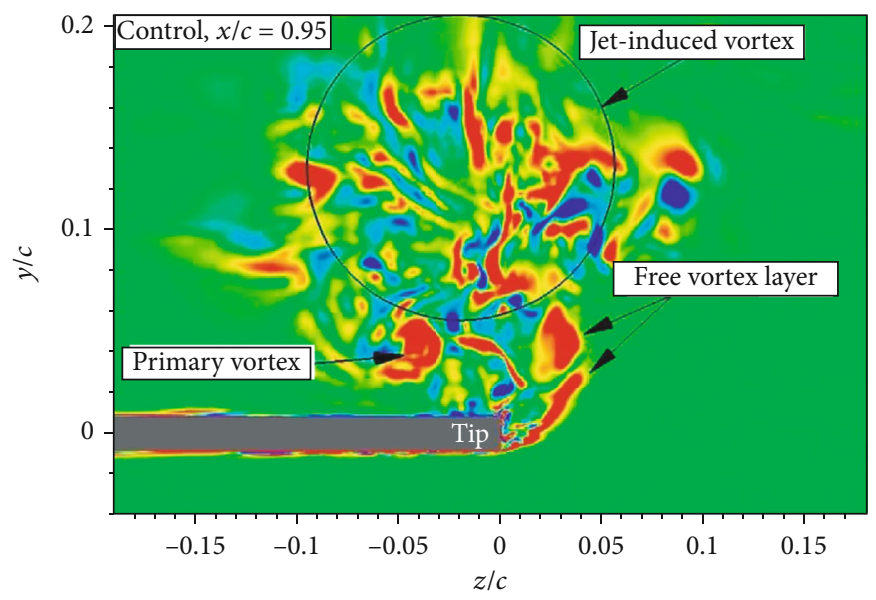

FIgURE 21: The instantaneous vorticity field near the trailing edge under normal blowing.

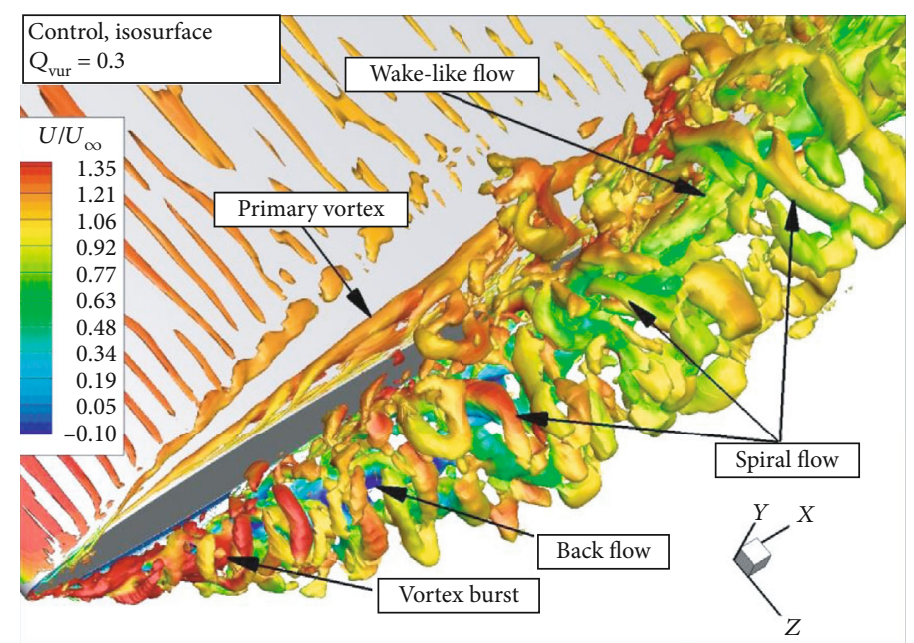

FIgURE 22: The structure of the induced vortex under normal blowing.

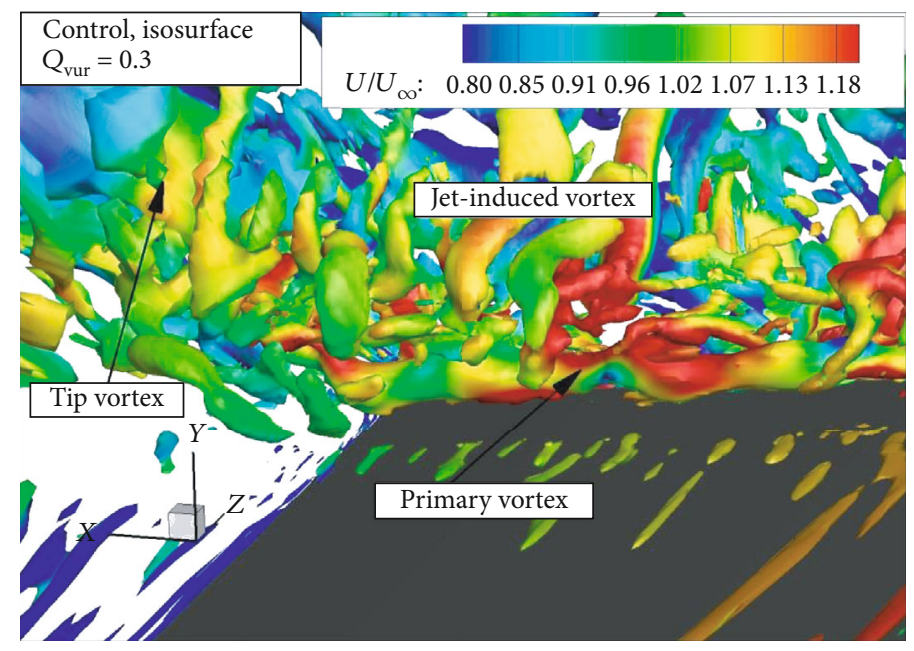

FIGURE 23: The structure of the wingtip vortex near the trailing edge under normal blowing. 


\section{Conclusions}

In this study, the normal blowing approach for controlling the wingtip vortex of a NACA0012 wing was studied using LES with the Smagorinsky-Lilly model. The flow field was analysed qualitatively and quantitatively, and some key parameters of the primary vortex were studied before and after normal blowing. The flow structures of the jet-induced vortex and primary vortex were further discussed in more detail. For the baseline clean airfoil, the primary vortex core is the jet-like flow structure whose axial velocity is larger than the freestream velocity. At the trailing edge, the secondary vortex and other free vortex layers converge to the primary vortex. The primary vortex plays a dominant role in the rolling up of the wingtip vortex. Normal blowing from the lower surface of the wingtip was utilized to control the concentrated wingtip vortex. It was found that normal blowing, which acts as a virtual endplate, can restrain the transverse flow around the primary vortex and the primary vortex tends to attenuate. In addition, the rolling up of the secondary vortex is accelerated by normal blowing and forms a stronger jetinduced vortex. A typical backflow can be observed in the jetinduced vortex, which turns into obvious spiral burst. It appears that the jet-like flow of the primary vortex decays and is converted to the wake-flow. Moreover, the spiral breakdown of the jet-induced vortex destroys the primary vortex and dominates the flow near the trailing edge. After normal blowing, the radius, maximum induced velocity, axial vorticity flux, and peak value of pressure of the primary vortex core decrease by $25 \%, 28 \%, 46 \%$, and $52 \%$, respectively.

\section{Data Availability}

The data used to support the findings of this study are included within the article.

\section{Conflicts of Interest}

The authors declare that there is no conflict of interest regarding publication of this paper.

\section{Acknowledgments}

The authors would like to thank Dr. Kun Zhao from the Key Lab of Aerodynamic Noise Control, China Aerodynamic Research and Development Centre, for all useful assistance within the course of this research.

\section{References}

[1] J. Wu, H. Ma, and M. Zhou, Introduction to Vorticity and Vortex Dynamics, Higher Education Press, 1993.

[2] T. Gerz, G. Holzäpfel, and D. Darracq, "Commercial aircraft wake vortices," Progress in Aerospace Sciences, vol. 38, no. 3, pp. 181-208, 2002.

[3] P. R. Spalart, “Airplane trailing vortices," Annual Review of Fluid Mechanics, vol. 30, no. 1, pp. 107-138, 1998.

[4] C. Breitsamter, "Wake vortex characteristics of transport aircraft," Progress in Aerospace Sciences, vol. 47, no. 2, pp. 89134, 2011.
[5] G. K. Batchelor, “Axial flow in trailing line vortices," Journal of Fluid Mechanics, vol. 20, no. 4, pp. 645-658, 1964.

[6] G. M. Williams, "Viscous modelling of wing-generated trailing vortices,” Aeronautical Quarterly, vol. 25, no. 2, pp. 143-154, 1974.

[7] E. R. Hoffmann and P. N. Joubert, "Turbulent line vortices," Journal of Fluid Mechanics, vol. 16, no. 3, pp. 395-411, 1963.

[8] D. W. Moore and P. G. Saffman, "Axial flow in laminar trailing vortices," Proceedings of the Royal Society of London. A. Mathematical and Physical Sciences, vol. 333, pp. 491-508, 1973.

[9] V. J. Rossow, "Lift-generated vortex wakes of subsonic transport aircraft," Progress in Aerospace Sciences, vol. 35, no. 6, pp. 507-660, 1999.

[10] Y. Jiang, Aircraft Winglet Design, Aviation Industry Press, 2009, (in Chinese).

[11] A. Uzun and M. Y. Hussaini, "A computation study on tip vortex noise," in 14th AIAA/CEAS Aeroacoustics Conference (29th AIAA Aeroacoustics Conference), Vancouver, BC, Canada, 2008.

[12] F. Albano, F. D. Gregorio, and A. Ragni, “Trailing vortex detection and quantitative evaluation of vortex characteristics by PIV technique," in International Congress on Instrumentation in Aerospace Simulation Facilities, Gottingen, Germany, 2003.

[13] J. Dacles-Mariani, S. Rogers, D. Kwak, G. Zilliac, and J. Chow, "A computation study of wingtip vortex flowfield," in $23 \mathrm{rd}$ Fluid Dynamics, Plasmadynamics, and Lasers Conference, Orlando, U.S.A., 1993.

[14] J. Dacles-Mariani, G. Zilliac, J. Chow, and P. Bradshaw, "Numerical/experimental study of a wingtip vortex in the near field," AIAA Journal, vol. 33, no. 9, pp. 1561-1568, 1995.

[15] B. R. Ramaprian and Y. X. Zheng, "Measurements in rollup of the tip vortex from a rectangular wing," AIAA Journal, vol. 35, no. 12, pp. 1837-1843, 1997.

[16] J. S. Chow, G. Zilliac, and P. Bradshaw, "Mean and turbulence measurements in the near field of a wingtip vortex," AIAA Journal, vol. 35, no. 10, pp. 1561-1567, 1997.

[17] D. Birch, D. Lee, F. Mokhtarian, and F. Kafyeke, "Structure and induced drag of a tip vortex," Journal of Aircraft, vol. 41, no. 5, pp. 1138-1145, 2004.

[18] W. J. Devenport, M. C. Rife, S. I. Liapis, and G. J. Follin, "The structure and development of a wing-tip vortex," Journal of Fluid Mechanics, vol. 312, pp. 67-106, 1996.

[19] E. A. Anderson and T. A. Lawton, "Correlation between vortex strength and axial velocity in a trailing vortex," Journal of Aircraft, vol. 40, no. 4, pp. 699-704, 2003.

[20] R. T. Whitcomb, A Design Approach and Selected Wing Tunnel Results at High Subsonic Speeds for Wing-Tip Mounting Winglets (NASA TN-D-8260), Natl. Aeronaut. Space Admin, Washington, DC, USA, 1976.

[21] W. He, Z. Niu, B. Pan, and Q. Lin, "Study on experiments for suppressing wingtip vortices with plasma," Engineering Mechanics, vol. 30, no. 5, pp. 277-281, 2013.

[22] H. HASEBE, Y. NAKA, and K. FUKAGATA, "An attempt for suppression of wing-tip vortex using plasma actuators," Journal of Fluid Science and Technology, vol. 6, no. 6, pp. 976988, 2011.

[23] J. Sun and X. Ming, "Effect of nonlinear gas oscillations on wing-tip vortices," Journal of Nanjing University of Aerospace \& Astronautics, vol. 36, no. 1, pp. 39-43, 2004. 
[24] J. WU, A. VAKILI, Z. CHEN, and F. GILLIAM, "Investigations on the effects of discrete wingtip jets," in 21st Aerospace Sciences Meeting, Reno, NV, U.S.A., 1983.

[25] D. A. Tavella, N. J. Wood, C. S. Lee, and L. Roberts, "Lift modulation with lateral wing-tip blowing," Journal of Aircraft, vol. 25, no. 4, pp. 311-316, 1988.

[26] Y. Han and J. G. Leishman, "Investigation of helicopter rotorblade-tip-vortex alleviation using a slotted tip," AIAA Journal, vol. 42, no. 3, pp. 524-535, 2004.

[27] A. L. Heyes and D. A. R. Smith, "Spatial perturbation of a wing-tip vortex using pulsed spanwise jets," Experiments in Fluids, vol. 37, no. 1, pp. 120-127, 2004.

[28] K. Duraisamy and J. D. Baeder, "Control of tip vortex structure using steady and oscillatory blowing," in AIAA Applied Aerodynamics Conference, Washington, DC, U.S.A., 2003.

[29] K. Duraisamy and J. D. Baeder, "Numerical simulation of the effects of spanwise blowing on wing-tip vortex formation and evolution," Journal of Aircraft, vol. 43, no. 4, pp. 996-1006, 2006.

[30] D. Greenblatt, "Fluidic control of a wing tip vortex," AIAA Journal, vol. 50, no. 2, pp. 375-386, 2012.

[31] S. C. Crow, "Stability theory for a pair of trailing vortices," AIAA Journal, vol. 8, no. 12, pp. 2172-2179, 1970.

[32] K. Yang, Experimental Study of Wingtip Vortex Control via Multi-Winglets and Tip Blowing, Dissertation for Master degree, Tsinghua University, 2012.

[33] P. Margaris and I. Gursul, "Vortex topology of wing tip blowing," Aerospace Science and Technology, vol. 14, no. 3, pp. 143$160,2010$.

[34] J. Smagorinsky, "General circulation experiments with the primitive equations," Monthly Weather Review, vol. 91, no. 3, pp. 93-99, 1963.

[35] D. K. Lily, "A proposed modification of the germano subgridscale closure method," Physics of Fluids, vol. 4, no. 3, pp. 633635, 1992.

[36] M. Germano, U. Piomelli, P. Moin, and W. H. Cabot, "A dynamic subgrid-scale eddy viscosity model," Physics of Fluids, vol. 3, no. 7, pp. 1760-1765, 1991.

[37] T. Imamura, S. Enomoto, and K. Yamamoto, "Noise generation around naca0012 wingtip using large-eddy-simulation," in 25th Congress of the International Council of the Aeronautical Sciences (ICAS), Hamburg Germany, 2006.

[38] T. Imamura, S. Enomoto, H. Kato, Y. Yokokawa, and K. Yamamoto, "Numerical simulation of NACA0012 wingtip flow leading to noise generation," in 11th AIAA/CEAS Aeroacoustics Conference, Monterey, California, U.S.A., 2005.

[39] J. C. R. Hunt, A. A. Wray, and P. Moin, "Eddies, stream, and convergence zones in turbulent flows," Center for Turbulence Research Report CTR-S88, 1988.

[40] A. Shekarriz, T. C. Fu, J. Katz, and T. T. Huang, "Near-field behavior of a tip vortex," AIAA Journal, vol. 31, no. 1, pp. 112-118, 1993.

[41] C. L. Burley, T. F. Brooks, B. G. V. D. Wall, H. Richard, and E. Mercker, "Rotor wake vortex definition using 3C-PIV measurements-corrected for vortex orientation," in 9th AIAA/CEAS Aeroacoustics Conference, Hilton Head, South Carolina, U.S.A., 2003. 